\title{
The Role of Modern Technologies in Promoting Values Among the Students Enrolled at the Faculty of Educational Sciences at the University of Jordan
}

\author{
Fahmieh Mohamad Hamed Abu - Sadeh \\ The Ministry of Education \\ Dr. Abd El-Salam Fahad Al-Awamrah \\ The University of Jordan
}

\begin{abstract}
The present study aimed to explore the role of modern technologies in promoting values among the students enrolled at the faculty of educational sciences at the University of Jordan. It aimed to explore that from the perspective of the students themselves. It targets (social, humanitarian, national, and aesthetic) values. A simple random sample was selected. It consists of 320 female and male university students. Those students are enrolled at the faculty of educational sciences at the University of Jordan. To meet the study's goals, a twenty-eight item questionnaire was developed. This questionnaire sheds a light on 4 areas. It was found that modern technologies play a moderate role in promoting values among the students enrolled at the faculty of educational sciences at the University of Jordan. That's because the overall mean is 3.43. It was found that there isn't any statistically significant difference -at the statistical significance level of $(a=0.05)$ - between the respondents' attitudes in this regard which can be attributed to gender or academic year. That applies to all the areas jointly and separately. Several recommendations are proposed by the researchers. For instance, the researchers recommend using social media by Jordanian universities in order to promote positive values among students
\end{abstract}

Keywords: modern technologies, promoting values

DOI: $10.7176 / \mathrm{JEP} / 11-2-03$

Publication date: January $31^{\text {st }} 2020$

\section{The Study's Background and Significance:}

During the contemporary era, a technological revolution is experienced by people in all the areas. Technology has been receiving much attention by people. In fact, people today can't give up the use of technology. That's because technology facilitates the way people carry out their tasks and communicate, regardless of the space separating them. Due to the emergence of technology, the word has become a small village. That's attributed to the invention of the internet service and the creation of the social media platforms. For instance, through using the internet and social media, people can practice audio-visual communication even if they live in different continents or countries. In addition, technology enables people to carry out difficult tasks with consuming the least amount of time and effort. Today, technology became an important part of daily life. It can't be given up by people, especially by young people who seek developing the nation and making positive changes.

Technology today plays a significant role in the educational field due to its benefits in this field. For instance, it enables students to communicate with each other. It enables students to communicate with their teachers through using email and chat rooms. It enables teachers to communicate with parents. It provides opportunities for expressing opinions. Having such opportunities shall enable people to benefit from others' opinions (Al-Shboul and Alyan, 2014).

According to Al-Ash'ab (2015), modern technologies today have many benefits. For instance, modern technologies facilitate the way people communicate with each other. They facilitate the way in which global forums are held and the way in which global news is shared. They enable any organization to make its own internal network. They enable people to share their expertise with their peers. They improve the organizational effectiveness and improve the quality of the provided education.

According to Hasan (2010), technology aims to increase the performance efficiency of individuals. It enables people to communicate regardless of the distance separating them. There is no doubt that ICT enables nations to cooperate with each other in political, social, economic, and educational areas. ICT enables people to avoid social elimination. It eliminates the geographical limitations separating people. To be specific, it plays a significant role in achieving economic, social and educational development (Al-Madani, 2015).

Technology has been increasingly used in the higher education field. Therefore, it has become necessary to utilize it effectively. Technology participates in improving the quality of the provided education. It participates in achieving advancement and excellence (Al-Qasas, 2010). To be specific, it has been dominating and developing various fields of life, including the educational field. It enables students to cooperate with their peers and interact with them (Marian \& Dumitriua, 2003). 
The technological revolution increased the demand for recruiting technical staff. It made a change in the way people communicate. It facilitated the way people live and carry out tasks (Aggarwal, 2001).The developed countries exert efforts constantly in order to keep up with the latest technologies and develop them. That's because technologies enable governments to meet their goals. In addition, technologies can be employed in a manner that is consistent with the dominant values in society. It can be employed for promoting specific values in society (Mahmoud, 2009).

Values play a significant role in people's lives. They serve as the ethical ground that govern people's acts in society. They govern the way people socially interact with each other. Proving attention to values shall enable the nation to develop. That's because values govern the way people work. It's because complying with values shall lead to having a society which individuals have strong social connections with each other. It's because values govern the social framework of society. Encouraging people to comply with values shall make such compliance an essential part of the culture. Values refer to a set of rules, goals, ideals, ideas, and measurements that are adopted by a group to classify things into good, \& bad, and right and wrong (Naser, 2016).

There is a debate among scholars about the meaning of the term (values). This term may be defined as how precious something or someone is (Abed Al-Qader, 2011). Values aim at regulating the behavior of all the categories in society. In the society that complies much with values, people respect each other much and enjoy high levels of internal peace. Complying with ideals shall make one's behavior very good. It shall make one show a high level of compliance with the religious principles. It shall lead people to show much respect to others' rights. That shall make one experience psychological stability. Values -e.g. handling responsibility and respecting others' freedoms- control people's behaviors. Some values- e.g. cooperation, honesty, and appreciation- can strengthen people's social relationships with one another. That shall lead to having a society which individuals have strong social connections with each other(Al-Sayed, 2005).

It should be noted that universities play a significant role in promoting values. That's because universities play a significant role in educating and developing the members of society. It's because universities play a significant role in training and developing human resources and qualifying them in scientific, practical and ethical areas. It's because universities play a significant role in raising up a good citizens whose behaviors are excellent and distinguished. Universities seek providing society with good citizens (i.e. citizens who are honest, having integrity and capable of handling responsibility)(Al-Aqil and Al-Hyari, 2014).

Universities are considered higher education institutions. They develop individuals to become capable of practicing a profession or taking an office in the future. They develop individuals in order to develop society and achieve advancement. They do that in order to enable the society to develop and advance. That's done through providing effective curriculum, and activities that seek promoting positive values (Al-Sharqawi, 2005).

Universities play a significant role in achieving development in the future. That's done through promoting specific social and intellectual orientations among students. Public and private universities exert much effort to educate people who shall handle national responsibilities, achieve development and comply with ethics. However, achieving that requires promoting community values among young people. Such promotion is needed, because there has been a decrease in the extent of complying with community values. In short, universities promote values among young people whose age is within the range of 18-22 years old. They prepare people to become capable of engaging in practical life and choosing a profession. There is no doubt that technology plays a significant role in people's lives. It should be noted that people use technology for various goals. Young people today are the ones who use technology the most. Thus, they shall accept the ideas promoted through technology. Therefore, one of the researchers of the present study use modern technologies in order to promote values among young people.

In the light of the aforementioned, the present study aimed to explore the effectiveness of modern technologies in promoting values among the students enrolled at the faculty of educational sciences at the University of Jordan.

\section{Modern technologies:}

Major scientific developments have been experienced and the number of scientific inventions has been increasing. In the light of that, the term "modern technologies" emerged during the previous decades. Modern technologies led to increasing the level of human wellbeing. They facilitated the way people live and carry out tasks. That's because educational, health, communication and transportation services today are delivered through using modern technologies.

Al-Kreety and Manhi (2014) suggest that the term (modern technologies) has emerged recently. However, the origins of this term go back to early ages. For instance, during early ages, humans used to use simple technologies, such as: simple equipment. That was done to meet needs and solve problems. Technologies have been developing in a continuous manner.

It has been proved that using modern technologies in the educational field has many benefits. For instance, such use shall develop students' thinking. It shall improve students' retention of information. It shall enable teachers to use various teaching methods for delivering the intended information. It shall enable teachers to use texts and audio and visual content for delivering the intended information. It shall enable teachers to eliminate the 
spatial and temporal limitations hindering them from communicating with their students. It shall strengthen the teachers' relationships with the students. It shall enable students to turn theoretical knowledge into practical one. That can be done through using videos and practical representation. It shall enrich students' vocabulary-related knowledge (Abeed, 2006).

Using modern technologies shall enable students to obtain information. It shall promote knowledge about the correct way to behave. It shall reduce people's ignorance about various issues. It shall promote knowledge among people about self-related concepts. Thus, it shall enable people to understand themselves and the world surrounding them in a better manner. It shall enable one to compare himself/ herself with others. It shall enable one to develop himself/herself professionally and/or personally. It shall facilitate the way people interact socially with each other. It shall fight against isolation and feelings of boredom (Shbeeta, 2014).

Modern technologies have changed the way individuals and groups think. They led to changing people's behaviors. The emergence of modern technologies is considered one of the impacts of globalism (Al-Yousif, 2012). Modern technologies involve a great number of technological equipment, programs and websites, such as: the social media websites.

Social media (SM) refers to several electronic websites. It emerged when the second generation of the World Wide Web (Web 2.0)emerged. It enables people who share a specific interest to communicate with each other in a virtual environment. It enables school students to communicate through the school's page on social media (Ben Da'oud, 2015, 20-21).

Social media allows people to message each other. It enables people to share photos or videos. It enables people to view others' profiles and follow their latest news. Social media platforms are considered web 2.0 applications. They are considered so, because they rely on the users' ability to interact with each other through sending friendship requests, or joining groups related to a specific interest or category. Such groups may include: the groups of lawyers, students or photographers. Some of the social media platforms are listed below (Athamneh, 2017).

1) Facebook (FB): It's the most important social media website. The Facebook profile displays brief information about one's life. It may be viewed by the ones who want to get to know to him/her and the ones who want to communicate with him/her. When using FB, one must use his/her real name and e-mail. Facebook posts the latest friends' news which may include :their latest personal news, photos, and videos.

2) Twitter: It's a social media website. It enables people to post tweets. The tweet mustn't exceed 140 letters. A Twitter page can be created through administering personal data, and email. All people can access such data (Ross et al., 2015).

3) YouTube: It's a social media website that allows its users to upload social, religious, political, educational and etc.. videos. It was created in 2005 by three individuals. It was created by PayPal Company in Prono, California, USA (Athamneh, 2017). The YouTube videos may be watched by millions of watchers within a few moments. YouTube includes videos about various aspects of life. It added features that increased the competition between YouTube users (Ata, 2010, 13).

In the light of the aforementioned information, it should be noted that there are various modern technologies. However, social media is the technology that has the greatest impact on young people. It may include: Facebook, Twitter, YouTube, and etc.. It facilitates the spread of ideas among people. It can affect many categories of people through convincing them with a specific opinion. It can affect the values adopted by the members of society.

\section{Values:}

Values serve as a significant factor affecting the society's orientations. Parents seek instilling values within one starting from the infancy stage. One's values develop in an ongoing manner. That's because the older one gets, the more mature he/she shall become. For instance, throughout life, one may adopt a belief, or a stereotypical idea that supports his/her positive/ or negative ideas.

Values are adopted by human societies only. That's because humans are the only creatures who adopt values. Thus, human and values are connected to one another. According to Kroeber, human and values serve as two faces of a single paper. If a specific society gave away its values, it means that it has given up its humanity (Al-Zyood, 2006, 21).

A human being without values is similar to a ship without its sail. For instance, the sail directs the ship. In a similar manner, values direct one in life to identify the right things and do beautiful and good deeds. Identifying the right thing is something sought by all people in life. In other words, identifying the truth is sought by all people. As for doing good deeds, it's also sought by people when doing actions. As for doing beautiful deeds, that shall enable one to develop which is the goal of art. Thus, humanity is manifested through identifying the right things and doing beautiful and good deeds. Values are shaped by one's beliefs and responses (Mattar, 2006).

Values play a significant role in shaping one's personality, national belonging, and knowledge. They play a significant role in shaping the society's orientations. In short, they have the greatest impact on shaping one's social and national identities(Patrick, 2011). 
Values are important elements of culture. They regulate that way in which one expresses himself/ herself. They meet one's artistic needs. They may change throughout time. Complying with values plays a significant role in the development of civilizations and the advancement of society (Al-Qaba', 2012).

The term (values) is a complex term. Values are connected to the philosophical heritage. They have been existing since the creation of human beings (Mahdi, 2012). In language, the term (value) may refer to how precisions or useful something is (Al-Fayrooz, 1994, 176).

In human and social sciences, there isn't one fixed definition for the term (value). However, this term has been defined as a set of latent principles and beliefs that areadopted by one for regulating his/ her behaviors in various areas, and relationships in society (Al-Zyood, 2006: 23). Abu Al-Naser (2008, 62) defines the term (value) as a set of measurements and principles that are considered important by all individuals. All people demand having compliance with values. Values manifest through positive behaviors that are preferred, carried out, and recognized by most of the society's members. Most of the society's members seek instilling the dominant values within their children (Abu Al-Naser, 2008, 62).

Parsons defines values as criteria that enable one to make his/ her choice in various situations. Thus, according to the latter researcher, values regulate one's behaviors (cited in Al-Jamal, 2013: 2). In psychology, value refers to the capacity of an item to meet a need. That applies whether this item is a thing is an object, person, event, or idea. In short, value refers to how precious something is. Thus, value is determined based on a subjective perspective. The value of an item may be inconsistent with its commercial value in the market (Abdullah, 2014: 121).

The researchers of the present study define values as a set of affective, cognitive and behavioral perceptions, and beliefs that are dominant in a specific society. Society adopts specific values after going through several experiences. The latte researchers suggest that values serve as criteria for classifying things into bad and good. They add that values are fixed.

Value are characterized with several characteristics that make them different from similar concepts, such as: beliefs, motives, needs and behaviors. They have been classified based on several criteria, such as: content, belief, and changeability (Al-Zyood, 2006).

Ahmad (2013) classify values into: scientific, economic, social, spiritual, ethical, national, aesthetic, cultural, cognitive, health, preventive, personality, human and religious values

Statement of the Problem and the Study's Questions:

Today, technology plays an essential role in life. In fact, it affects the values adopted by society. That is because technology plays a significant role in delivering news. It's because technology affect the intellectual orientation of young people because it's used much by young people. It's because technology plays a significant role in promoting positive values among young people. Such promotion is needed because there has been a decrease in the extent of complying with positive values by young people. Such decrease can be manifested through the increase of the rates of the violent crimes that are committed by young people in universities. It can be manifested in the increase of the rate of committing plagiarism and assault crimes against the professors working at universities.

It should be noted that modern technologies can significantly affect the value system of university students. That's because young people are highly interested in using modern technologies. The researchers of the present study noticed that young people are highly attached to the use of modern technologies. That was concluded based on practical experiences. Therefore, the researchers of the present study aimed to explore the role of modern technologies in promoting values among the students enrolled at the faculty of educational sciences at the University of Jordan. The problem of the present study can be manifested in the following questions:

Q.1 What is the role of modern technologies in promoting (social, humanitarian, national, and aesthetic) values among the students enrolled at the faculty of educational sciences at the University of Jordan from the perspective of the students' themselves?

Q.2 Is there any statistically significant difference - at the statistical significance level of $(a=0.05)$ - between the respondents' attitudes which can be attributed to gender and academic year?

\section{The Study's Objectives:}

The present study aimed to identify the role of modern technologies in promoting (social, humanitarian, national, and aesthetic) values among the students enrolled at the faculty of educational sciences at the University of Jordan. It aimed to explore that from the perspective of the students' themselves. It aimed to identify whether there is any statistically significant difference -at the statistical significance level of $(a=0.05)$ - between the respondents' attitudes which can be attributed to gender and academic year.

\section{The Study's Significance:}

The present study is significant because it aimed to shed a light on a very important subject (i.e. modern technologies). This subject is considered important, because university students spend most of their time using 
such technologies. The present study is considered significant because it is useful for the categories listed below:

1- The officials working at the Ministry of Higher Education. For instance, such officials shall be encouraged to enlist the values mentioned in this study within the official goals of higher education.

2- The professors working at universities: The present study shall enable those professors to develop the value system of university students.

3- The curricula developers: The present study shall encourage curricula developers to enlist positive values within curricula.

4- The local community institutions: The present study shall enable those institutions to develop the value system of the society's members

5- The researchers interested in this subject: The present study shall enrich the theoretical framework of the studies addressing a similar subject. It shall assist the researchers addressing a similar subject when developing an instrument.

\section{Definitions}

Role: (operational definition): It refers to the role of Jordanian universities in promoting (social, humanitarian, national, and aesthetic) values among university students. Values are promoted by Jordanian universities through carrying out several measures and procedures.

Values: (theoretical definition): They refer to a set of rules, goals, ideals, ideas, and measurements that are adopted by a group to classify things into good, \& bad, and right and wrong. They regulate people's behaviors. The non-compliance with values shall lead to punishments enforced by the group (Naser, 2016, 145).

Values: (operational definition): They refer to a set of (social, humanitarian, national, and aesthetic) values adopted by the faculty of educational sciences at the University of Jordan. Compliance with values manifest through one's daily interaction with others. Values affect way university students behave within the university. The values targeted by the researchers of the present study are listed below:

1- Social values: They include the values related to: time management, sympathy with colleagues, interaction among students, patience, addressing problems with positivity, positive communication with students.

2- humanitarian values: They include the values related to: honesty, forgiveness, accepting others, community service, personal freedom, religious dialogue, collaboration with students

3- National values: They include the values related to: national belonging, fighting against fanaticism and corruption, promotion of national values and compliance with rules and laws.

4- Aesthetic values: They include the values related to: good taste in music, verbal expression, promotion of a good image for the university, beautifying campus, preserving the university's facilities, hygiene, and attention to personal appearance.

Modern technologies: (theoretical definition): They refer to assistant technologies that are used for increasing the quality of the provided education. They aim at developing the provided education and facilitating the process of delivering knowledge. They serve as an essential part of the educational process. They refer to several technological equipment and means (Satel, 2018: 34)

Modern technologies (operational definition): They refer to several equipment and devices that are used by the University of Jordan. They include: the World Wide Web (WWW) and social media (e.g. Facebook and Twitter). They include any electronic website used by the University of Jordan. They refer to any device or program used by the faculty members at the University of Jordan for teaching students. They may be used in social and daily life.

The faculty of educational sciences: (operational definition): It is one of the humanitarian sciences faculties at the University of Jordan. It was established in 1972. 19773 faculty members started to teach at it. It grants its students BA, MA, and PhD degrees. It includes the following departments: 1)-curriculum and instruction, 2) Educational administration and foundations, 3)- Educational psychology, 4)- Counseling and special education, 5)-library and information.

\section{Limits and limitations}

The present study aimed to explore the role of modern technologies in promoting (social, humanitarian, national, and aesthetic) values among the students enrolled at the faculty of educational sciences at the University of Jordan. It aimed to explore that from the perspective of the students' themselves. The limits of the present study are:

1- Thematic limits: The present study targets the role of modern technologies in promoting values among the students

2- Human limits: The present study targets a sample of BA students who are enrolled at the faculty of educational sciences at the University of Jordan

3- Spatial limits: The present study was conducted at the faculty of educational sciences at the University of Jordan 
4- Temporal limits: The present study was conducted during the first semester of the academic year (20192020)

\section{Previous Studies}

\section{First: Studies in Arabic language}

Al-Shamas (2005) conducted a field study. He aimed to explore the impact of foreign TV channels on young people. He targeted the students at the faculty of education at Damascus University. To meet the study's goals, a social survey approach was adopted. For instance, a survey was developed by the researcher to collect data. The population consists from all the $4^{\text {th }}$ year students enrolled at the faculty of education at Damascus University. The sample consists from 116 female and male students. It was found that students have shown a decline in academic performance due to watching foreign TV channels for a period of -5 hours per day. It was found that there are statistically significant differences between the respondents' attitudes which can be attributed to gender, for the favor of males. It was found that there are statistically significant differences between the respondents' attitudes which can be attributed to the place of residence for the favor of the ones living in the city.

Al-Mbaydeen (2009) aimed to identify the extent of using modern technologies (TV channels, internet, and mobile) by the respondents. He also aimed to identify the role of such technologies in committing delinquent acts by juveniles. He aimed to identify the role of such technologies in educating juveniles in Jordan. To meet the study's goals, a survey was developed by the researcher to collect data. 283 juveniles were sampled. It was found that there are statistically significant differences between the respondents' commitment of delinquent acts which can be attributed to gender for the favor of females. It was found that there are statistically significant differences between the respondents' commitment of delinquent acts which can be attributed to income for the favor of the families which income is greater than 700 JDs. It was found that there are statistically significant differences between the respondents' commitment of delinquent acts which can be attributed to the parents' marital status for the favor of the divorced parents. It was found that there are statistically significant differences between the respondents' commitment of delinquent acts which can be attributed to the parents' academic qualification. It was found that there are statistically significant differences between the respondents' commitment of delinquent acts which can be attributed to the place of residence for the favor of the ones living in the city. It was found that there are statistically significant differences between the respondents' commitment of delinquent acts which can be attributed to the juvenile's academic level for the favor of the illiterate ones. It was found that there isn't any statistically significant difference between the respondents' commitment of delinquent acts which can be attributed to the type of accommodation, mother's academic qualifications and the juvenile's age.

Al-Shahin (2010) aimed to explore the impact of social, economic and religious values on the teaching profession. The sample consists from 730 female students enrolled in the teacher development institutions. These students are also enrolled at the faculty of education at Kuwait University. Those students practice the teaching profession. A twenty-one item questionnaire was used. It covers several areas; (social, economic and religious areas). The religious values are ranked first, whereas the economic values are ranked second. The social values are ranked third. It was found that there isn't any statistically significant difference between the respondents' attitudes which can be attributed to major. It was found that there is a statistically significant difference between the respondents' attitudes which can be attributed to the marital status for the favor of the female married students. It was found that there is a statistically significant difference between the respondents' attitudes which can be attributed to the place of residence for the favor of the ones living in areas that are more civilized.

Al-Zboun et al. (2012) aimed to explore the impact of social media on shaping the value system of the students enrolled in Ajloun University College. A forty four item questionnaire was used for data collection. The sample consists from 175 students who were randomly selected. It was found that there is a significant positive relationship between using social media and the formation of the value system of the students enrolled in Ajloun UniversityCollege.

Al-Tayar (2014) aimed to explore the impact of social media- specifically Twitter-- on the values of university students. An analytical descriptive approach was adopted and a questionnaire was developed for collecting data. 2274 male students were sampled. They were selected from King Saud University. It was found that the use of Twitter led students to create illegitimate relationships. It was found that the use of Twitter led to a decline in the extent of practicing the religious rituals. It was found that the use of Twitter led to having more courage when talking to females.

Al-Abideen (2014) aimed to explore the impact of social media (Facebook, Twitter, and YouTube) on the social, religious, and political values of the students enrolled at Jordanian universities. To meet the study's goal, a social survey approach was adopted. For instance, a survey was used for collecting data. The sample consists from 866 female and male university students. They were selected from 4 private and public universities that are located in Amman. It was found that social media has positive impacts on the promotion some social values. For instance, social media encourages people to work and make achievements. It encourages people to use new terms. It was found that the respondents show a lack of compliance with religious values. It was found that social media 
participates in promoting religious tolerance and political values. For instance, social media participates in fostering national identity.

Shbeeta (2014) aimed to explore the effective role of using social media and personal websites in fostering dialogue among family members. He aimed to explore that from the parents' perspective. To meet the study's goals, 310 parents were chosen from 3 Palestinian cities; Gaza, Khan Younes, and the central governorate. An analytical descriptive approach was adopted and a questionnaire was developed for collecting data. It was found that $92 \%$ of the sons and daughters use social media. It was found that $76 \%$ of the sons and daughters use Facebook. It was found that $6.8 \%$ of the sons and daughters use Twitter. It was found that $16.8 \%$ of the sons and daughters use YouTube. It was found that using social media has a moderate impact on fostering dialogue among family members.

Al-Madani (2015) aimed to explore the role of SM in the creation of public opinion among Saudi university students. A descriptive approach was adopted. The sample consists from 200 female and male students who are enrolled at Um Al-Qura University. A twenty-one item questionnaire was used. It was found that $42 \%$ of the respondents believe that social media plays a very significant role in creating public opinion. It was found that $55 \%$ of the respondents believe that social media plays a moderate role in creating public opinion. It was found that $3 \%$ of the respondents believe that social media plays a poor role in creating public opinion. It was found that there are statistically significant differences between the respondents' attitudes which can be attributed to the extent of using social media.

Al-Omari (2015) aimed to explore the extent of compliance with values among the students enrolled at Jordanian universities. To meet the study's goal, a fifty-three item questionnaire was developed. This questionnaire covers five areas. The questionnaire forms were distributed to 1191 female and male students who were selected from the University of Jordan and Al-Ahliyya Amman University. Those students were selected from various human and scientific sciences faculties. The latter researcher conducted his study during the second semester of the academic year (2012-2013). It was found that the extent of compliance with values by the respondents is high. In terms of the extent of compliance with values, values are ranked as follows respectively: (intellectual, social, political, aesthetic and economic) values. It was found that there are statistically significant differences between the respondents in terms of the extent of complying with social and political values which can be attributed to the type of faculty. The latter differences are for the favor of the students enrolled at human sciences faculties. It was found that there are statistically significant differences between respondents in terms of the extent of complying with social and intellectual values which can be attributed to gender. The latter differences are for the favor of the female students. It was found that there are statistically significant differences between respondents in terms of the extent of complying with religious and intellectual values which can be attributed to academic year for the favor of freshmen. In the light of the study's results, the latter researcher recommends promoting the values that students show the lowest level of compliance with them. He recommends promoting values among students of various academic levels.

Al-Sharqi et al. (2015) aimed to explore the impact of social media on students' social behavior. They used a questionnaire. The sample consists from 2605 students. It was found that social media affects students social behavior and exposes students to bad people and negative ideas. It was found that social media makes students less sociable, reduces their productivity levels and distract them. It was found that social media makes students physically inactive.

Al-Dali and Al-Laithi (2016) aimed to explore the effects of social network on the values of the students in rural areas in Egypt. The sample was selected from El-Azhar University. It was found that most of the respondents use social network to communicate with peers. It was found that two third of the respondents are affected by the foreign values promoted through social network. It was found that there is a significant relationship between labor values and using internet. Two third of the respondents do not trust the news posted on social media.

Al-Helalat (2016) aimed to explore the role of technology -specifically Facebook and mobile phones- in initiating a value-based conflict among young people in the Jordanian family. To meet the study's goals, she used a questionnaire for collecting data. She selected a sample that consists from 1220 female and male young individuals. Those individuals were selected from the Jordanian society. It was found that the misuse of Facebook is greater than the misuse of mobile phones for the commitment of e-violence crimes and other crimes that emerged recently. It was found that the use of technology shall significantly increase the initiation of a value-based conflict within young people in the Jordanian family. It was found that young people in the Jordanian family suffer much from many manifestations of a value-based conflict due to the spread of technology.

Alshraah (2017) aimed to explore the impact of social media on promoting moral and religious values among Jordanian students. The sample consists from 210 male and female students of Hashemite University. A questionnaire was used. It was found that there isn't any significant relationship between social media and moral values. It was found that there is a significant relationship between social media and religious values. It was found that social media is used much by students.

Al-Agha and Esleem (2018) aimed to explore the role of social media (SM) in promoting social values among 
the students enrolled at Palestinian universities. They aimed to provide suggestions for activating the role of Palestinian universities in promoting social values. To meet the study's goals, the researchers adopted an analytical descriptive approach. A twenty-eight item questionnaire was developed. It covers three areas. The questionnaire forms were distributed to the members of the selected random sample. The sample consists from 220 female and male students. Those students were selected from the Islamic University of Gaza and the University of Palestine during the academic year (2016-2017). It was found that social media plays a significant role in promoting social values. It was found that there isn't any statistically significant difference between the respondents' attitudes which can be attributed to gender, faculty, or the number of hours spent on using social media. It was found that there is a statistically significant difference between the respondents' attitudes which can be attributed to university for the favor of the ones enrolled at the University of Palestine.

Al-Zboun and Ateyeh (2018) aimed to explore the negative impacts of modern communication technologies on raising up adolescents. They aimed to explore that from the perspective of the teachers working at Jordanian public schools. The sample consists from 450 female and male teachers. A descriptive approach was adopted. A thirty-two item questionnaire was used. It was found that using modern communication technologies has negative impacts on raising up adolescents. The study's areas are ranked respectively as follows: (healthcare, sexual, psychological, emotive, ethical, religious, social and economic areas).

\section{Foreign studies}

Michale (2010) aimed to explore the impact of using modern technologies -specifically social media- on social relationships. An analytical descriptive approach was adopted. The study's sample consists from 1600 young men. Those men were selected from Britain. A questionnaire was used for collecting data. It was found that $53 \%$ of the respondents spend time on Facebook that is greater than the time they spend on talking with their real friends or relatives. It was found that the respondents communicate with their friends through using SM more than communicate with them through making phone calls. It was found that respondents keep up with the latest news posted on social media more than keeping up with the latest new broadcasted through TV channels.

Mathur \& Corley (2014) aimed to explore the amount of knowledge about latent value-related concepts. They aimed to shed a light on the conceptual framework of the ethical behaviors in US schools. They held a workshop with parents and students to discuss value-related issues. They held a workshop with students to discuss the benefits of exchanging novels. They aimed to shed a light on the researchers' recommendations that concern ethics in education. They conducted a case study targeting a teacher who teaches a classroom including disabled children. Those children were suffering from behavioral and emotive disabilities. It was found that the latter teacher played an effective role in encouraging students to practice good ethical behaviors. It was found that US schools play an effective role in changing behavior. It was found that US schools play an effective role increasing an environment that is physically and emotionally secure. It was found that US schools play an effective role in promoting values (e.g. values related to professionalism, being caring, justice, and constructive criticism). It was found that US schools play an effective role in encouraging students to engage in classroom discussions and the activities that aim at promoting ethics. That shall encourage students to handle the responsibility of their own behaviors.

Aljaad (2016) aimed to explore the role of social media in educating Saudi women from the perspective of the male students enrolled at the faculty of education at King Saud University in Riyad. He used a questionnaire. The questionnaire forms are distributed to 500 female students. It was found that $95 \%$ of the respondents believe that social media has improved the way they interact with others and instilled a sense of responsibility within them. It was found that $61 \%$ of the respondents believe that social media plays a significant role in promoting democracyrelated values and creating an appropriate political culture. It was found that $9 \%$ of the respondents believe that social media is useful for obtaining social consultations. It was found that $84 \%$ of the respondents believe that social media is useful for establishing relationships with the ones interested in specific scientific subjects. The latter respondents also believe that social media enables them to exchange expertise with others.

Kara\&Tekin (2017) aimed to explore the relationship between using social media and humanitarian values among secondary school students. An analytical descriptive approach was adopted and a questionnaire was used. The study's population consists from $7^{\text {th }}$ and $8^{\text {th }}$ grade students. The sample consists from 1952 students who were selected from nine schools. It was found that using social media led to a decrease in the extent of complying with humanitarian values. It was found that there are statistically significant differences between the extent of complying with humanitarian values which can be attributed to gender for the favor of males.

Comments on the previous studies and the difference between the present study and the previous studies:

Some of the previous studies aimed to shed a light on modern technologies in universities. Such studies include: the ones conducted by Al-Mbaydeen (2009) and Al-Tayar (2014). Some of the previous studies aimed to shed a light on values. Such studies include: the ones conducted by Al-Helalat (2016) and Mathur \& Corley (2014). There are differences between the previous studies in terms of variables and the relationships they aimed to explore. As for the present study, it is similar to the studies conducted by Kara \& Tekin (2017) and Hussein (2016). That's because the latter studies aimed to shed a light on modern technologies and values jointly. 
There are differences between the previous studies in terms of population, sample and the countries they were conducted at. For instance, the study of Mathur \& Corley (2014) was conducted at the United States of America, whereas the study of Michale (2010) was conducted in Britain. In addition, some of the previous studies were conducted in Jordan, such as: the ones conducted by Al-Helalat (2016), andAl-Abideen (2014). There are differences between the previous studies in terms of sample. For instance, university students were sampled by Al-Shamas (2005), Al-Tayar (2014), and Al-Abideen (2014). As for the study of Al-Mbaydeen (2009), it targets juveniles. As for the study of Mathur \& Corley (2014), it targets school students.

There are differences between the previous studies in terms of the adopted approach. For instance, a social survey approach was adopted by Al-Shamas (2005) and Al-Abideen (2014). A descriptive approach was adopted by Al-Tayar (2014) \& Michale (2010). As for the present study, it adopts a developmental descriptive approach.

The researchers of the present study benefitted from the previous studies. For instance, they used the previous studies to enrich the literature of the present study. In addition, the previous studies provided the researchers of the present study with knowledge and information about the subject. They enable the researchers to draft the study's problems, and determine the study's approach, and measures. In addition, they provided the researchers with studies, theses and dissertations about the same subject.

The present study is distinguished from the previous studies. That's because the present study doesn't aimed at shedding a light on the negative impacts of modern technologies. In fact, the present study aimed to shed a light on the role of the latter technologies in promoting values. The present study is distinguished from the previous studies, because it targets four types of values, instead of targeting one type.

\section{Methods and procedures \\ The Study's Approach:}

The researchers of the present study adopts a developmental descriptive approach. They adopt this approach in order to explore the role of modern technologies in promoting values among the students enrolled at the faculty of educational sciences at the University of Jordan. They aimed to explore that from the perspective of the students themselves. They target (social, humanitarian, national, and aesthetic) values. The descriptive approach is usually adopted by researchers for providing a sensory description for items, and objects. It may be adopted to identify whether the sensory attributes of items and objects are accepted or not. It may be adopted to investigate and explore variables (Lawless and Heymann, 1999).

\section{The Study's Population and Sample:}

The study's population consists from all the students enrolled at the faculty of educational sciences at the University of Jordan during the first semester of the academic year (2019-2020). In specific, it consists from 30223 students. The sample was selected through using the simple random sampling method. It consists from 320 female and male students. Further details about that are presented through table (1) below.

Table (1): The distribution of the members of the sample in accordance with the study's variables (gender, and academic year)

\begin{tabular}{|c|c|c|c|}
\hline Variable & Category & Frequency & Percentage \\
\hline \multirow{3}{*}{ Gender } & Female & 244 & $76.3 \%$ \\
\cline { 2 - 4 } & Male & 76 & $23.8 \%$ \\
\cline { 2 - 4 } & Total & 320 & $100 \%$ \\
\hline \multirow{3}{*}{ Academic year } & $1^{\text {st }}$ year & 93 & $29.1 \%$ \\
\cline { 2 - 4 } & $2^{\text {nd }}$ year & 114 & $35.6 \%$ \\
\cline { 2 - 4 } & $3^{\text {rd }}$ year & 84 & $26.3 \%$ \\
\cline { 2 - 4 } & $4^{\text {th }}$ year & 29 & $9.1 \%$ \\
\hline & Total & 320 & $100 \%$ \\
\hline
\end{tabular}

\section{The Study's Instrument:}

The researchers developed an instrument after reviewing the relevant literature and previous studies. The instrument consists from several items. These items aim at exploring the role of modern technologies in promoting values among the students enrolled at the faculty of educational sciences at the University of Jordan. They aim at exploring that from the perspective of the students themselves. They target (social, humanitarian, national, and aesthetic) values. The initial version of the questionnaire consists from 25 items that cover 4 areas.

\section{Validity of the Instrument}

To check the instrument's validity, the initial version of the questionnaire was passed to 8 experts. Those experts are specialized in the relevant field and possess much expertise. They work as faculty members at the faculty of educational sciences at the University of Jordan. They were asked to assess the instrument in terms of content, 
relevancy, and language. They were asked to make the necessary adjustments to the questionnaire. That applies whether such adjustment are: deletions, additions, or changes. The researchers of the present study made adjustments to the questionnaire based on the experts' comments. For instance, they re-drafted some of the items. The final version of the questionnaire consists from 28 items that cover 4 areas. Further details about that are presented below:

- Social values: There are 7 items that shed a light on them.

- humanitarian values: There are 7 items that shed a light on them

- National values: There are 7 items that shed a light on them

- Aesthetic values: There are 7 items that shed a light on them

The five point Likert scale was adopted. This scale consists from the following categories: (To a very great extent /to a great extent/ to a moderate extent/ to a small extent/ to a very small extent).

Reliability of the Instrument:

To measure the reliability of the instrument, the researcher measured it through using two methods. The first method for measuring reliability is represented in the test-re-test method. Through this method, the questionnaire forms were distributed to an exploratory sample whose members aren't included in the actual sample. The exploratory sample consists from 30 female and male students. The questionnaire forms were distributed again to the same exploratory sample with a time interval of 2 weeks. After that, the Pearson correlation coefficient values were calculated. They are within the range of $0.77-0.82$. The total Pearson correlation coefficient value is 0.88 . The second method for measuring reliability is represented in calculating Cronbach alpha coefficient values. The latter values are within the range of 0.69-0.73. They are accepted values. The total Cronbach alpha coefficient value is 0.87 .Further details are listed below:

Table (2): Pearson correlation coefficient values and Cronbach alpha coefficient values

\begin{tabular}{|c|c|c|c|c|}
\hline \multirow{2}{*}{ No. } & Area & Number of items & \multicolumn{2}{|c|}{ Reliability coefficient values } \\
\cline { 3 - 5 } & & & $\begin{array}{c}\text { Pearson correlation } \\
\text { coefficient value }\end{array}$ & $\begin{array}{c}\text { Cronbach alpha } \\
\text { coefficient value }\end{array}$ \\
\hline 1. & Social values & 7 & 0.79 & 0.72 \\
\hline 2. & $\begin{array}{c}\text { humanitarian } \\
\text { values }\end{array}$ & 7 & 0.82 & 0.73 \\
\hline 3. & National values & 7 & 0.80 & 0.73 \\
\hline 4. & Aesthetic values & 7 & 0.77 & 0.69 \\
\hline & Total & $\mathbf{2 8}$ & $\mathbf{0 . 8 8}$ & $\mathbf{0 . 8 7}$ \\
\hline
\end{tabular}

\section{Criteria for classifying means:}

The five point Likert scale was adopted. This scale consists from the following categories: (To a very great extent /To a great extent/ To a moderate extent/ To a small extent/ to a very small extent). These categories stand for the following scores respectively: 5,4,3,2 and1.

To determine the interval between each two criteria, the following equation was used:

(The highest value -the least value) / The number of the required categories

$=(5-1) / 3=1.33$

Thus, the following criteria are adopted to classify means:

Low: $1-2.33$

Moderate: 2.34- 3.67

High: $3.68-5$

The study's variables:

The study's variables are listed below:

First: Mediating variables:

-Gender: It involves two categories (i.e. male and female)

Academic year: It involves 4 categories (i.e. $1 \mathrm{st}, 2 \mathrm{nd}, 3 \mathrm{rd}$, and 4 th year)

Second: Dependent variable: It's represented in role of modern technologies in promoting values among the students enrolled at the faculty of educational sciences at the University of Jordan from the perspective of the students' themselves. Such role is explored through calculating means

\section{Statistical analysis:}

The researchers used several statistical analysis methods. These methods are: (means, standard deviations, multivariate analysis of variance (MANOVA), three-way analysis of variance, and Scheffe post-hoc test. The latter 
test is conducted to conduct a comparison between three variables or more. The analysis of variance is conducted by researchers to have numerical results that can be employed for making multiple comparison calculations. It's considered one of the multiple comparison methods (MCMs) (Rafter et al., 2002). As for the Scheffe post-hoc test, it used for exploring complex relationships. It's used only for conducting paired comparisons (Kim, 2015)

\section{Results and discussion:}

\section{First: The results related to the first question}

Q.1 What is the role of modern technologies in promoting (social, humanitarian, national, and aesthetic) values among the students enrolled at the faculty of educational sciences at the University of Jordan from the perspective of the students' themselves?

To answer this question, means, and standard deviations were calculated, and levels and ranks were identified. Table (3): Means, and standard deviations, levels and ranks of the role of modern technologies in promoting values

\begin{tabular}{|c|c|c|c|c|c|}
\hline No. & Type of values & Mean & Std. & Rank & Level \\
\hline 4 & Aesthetic values & 3.50 & .614 & 1 & Moderate \\
\hline 1 & Social values & 3.50 & .636 & 2 & Moderate \\
\hline 2 & Humanitarian values & 3.41 & .645 & 3 & Moderate \\
\hline 3 & National values & 3.31 & .666 & 4 & Moderate \\
\hline & Total & 3.43 & .507 & & Moderate \\
\hline
\end{tabular}

*The means are listed based on the descending order

Table (3) shows that the means are within the range of 3.31-3.50. Thus, modern technologies play a moderate role in promoting values among the students enrolled at the faculty of educational sciences at the University of Jordan. That is concluded from the perspective of the students themselves. The total mean is 3.43 which is moderate. The total standard deviation is 0.507 . Aesthetic values are ranked first, because their mean is 3.50 . The latter mean is moderate. The standard deviation of the latter values is .614. Social values are ranked second, because their mean is 3.50 . The latter mean is moderate. The standard deviation of the latter values is 0.636 . Humanitarian values are ranked third, because their mean is 3.42. The latter mean is moderate. The standard deviation of the latter values is 0.645 . National values are ranked fourth, because their mean is 3.31 . The latter mean is moderate. The standard deviation of the latter values is 0.666 .

The researchers believe that the latter result is attributed to the fact that the Jordanian society is characterized with showing much compliance with values. They believe that this result is attributed to the fact that university students are adults, and well-educated who are capable of using modern technologies in a manner that doesn't negatively nor positively affect their compliance with social, humanitarian, national, and aesthetic values.

The latter result is inconsistent with the result concluded by Al-Helalat (2016). For instance, the latter researcher found that the use of technology shall significantly increase the initiation of a value-based conflict within young people in the Jordanian family. He also found that young people in the Jordanian family suffer much from many manifestations of a value-based conflict due to the spread of technology. The latter result is inconsistent with the result concluded by Al-Zboun and Ateyeh (2018). The latter researchers found that using modern communication technologies has negative impacts on raising up adolescents. The latter result is inconsistent with the result concluded by Kara \& Tekin (2017). The latter researchers found that using social media led to a decrease in the extent of complying with humanitarian value. As for the researchers of the present study, they found that modern technologies play a moderate role in promoting values among the students enrolled at the faculty of educational sciences at the University of Jordan.

Means, and standard deviations are calculated, and levels and ranks are identified. That is done to explore the role of modern technologies in promoting (social, humanitarian, national, and aesthetic) values among the students enrolled at the faculty of educational sciences at the University of Jordan. The researchers of the present study aimed to explore that from the perspective of the students themselves. Tables (4-7) shed a light on this role. 
Table (4): Means, and standard deviations, levels and ranks of the role of modern technologies in promoting aesthetic values

\begin{tabular}{|c|l|c|c|c|c|}
\hline No. & \multicolumn{1}{|c|}{ Statement } & Mean & Std. & Rank & Level \\
\hline 28 & $\begin{array}{l}\text { Modern technologies encourage students to provide more attention } \\
\text { to their personal appearance }\end{array}$ & 4.04 & .791 & 1 & High \\
\hline 22 & $\begin{array}{l}\text { Modern technologies participate in improving the students' taste in } \\
\text { music }\end{array}$ & 3.72 & .908 & 2 & High \\
\hline 23 & $\begin{array}{l}\text { Modern technologies provide students with opportunities to express } \\
\text { their ideas verbally }\end{array}$ & 3.50 & .995 & 3 & Moderate \\
\hline 26 & $\begin{array}{l}\text { Modern technologies encourage students to promote a good image } \\
\text { for their university }\end{array}$ & 3.38 & 1.058 & 4 & Moderate \\
\hline $\begin{array}{l}\text { Modern technologies provide students with opportunities to } \\
\text { paintings, and making decorations) }\end{array}$ & $\begin{array}{l}\text { Modern technologies provide students with opportunities to } \\
\text { preserve the university's facilities }\end{array}$ & 3.27 & 1.145 & 6 & Moderate \\
\hline 27 & $\begin{array}{l}\text { Modern technologies promote knowledge among students about the } \\
\text { concepts related to public hygiene }\end{array}$ & 3.26 & 1.142 & 7 & Moderate \\
\hline & \multicolumn{1}{|c|}{ Total } & 3.50 & .614 & & Moderate \\
\hline
\end{tabular}

*The means are listed based on the descending order

Based on table (4), the means are within the range of 3.26-4.04. Statement (28) shows a mean of 4.04 which is high and ranked first. It states the following: (Modern technologies encourage students to provide more attention to their personal appearance). The standard deviation of the latter statement is 0.791 . Statement (27) shows a mean of 3.26 which is moderate ranked last. It states the following (Modern technologies promote knowledge among students about concepts related to public hygiene). The standard deviation of the latter statement is 1.142 . It was found that modern technologies play a moderate role in promoting aesthetic values among the students enrolled at the faculty of educational sciences at the University of Jordan. That's because the overall mean is 3.50 which is moderate. The overall standard deviation is.614

Table (5): Means, and standard deviations, levels and ranks of the role of modern technologies in promoting social values

\begin{tabular}{|r|l|r|r|r|r|}
\hline No. & Statement & Mean & Std. & Rank & Level \\
\hline 6 & $\begin{array}{l}\text { Modern technologies facilitate the way students communicate with } \\
\text { each other }\end{array}$ & 3.68 & 1.119 & 1 & High \\
\hline 1 & Modern technologies enable students to manage their time & 3.66 & 1.036 & 2 & Moderate \\
\hline 2 & Modern technologies promote feelings of sympathy among students & 3.53 & .916 & 3 & Moderate \\
\hline 3 & Modern technologies enable students to develop a social network & 3.48 & 1.023 & 4 & Moderate \\
\hline 7 & $\begin{array}{l}\text { Modern technologies encourage students to interact positively with } \\
\text { each other }\end{array}$ & 3.45 & 1.099 & 5 & Moderate \\
\hline 5 & Modern technologies enable students to address problems positively & 3.41 & 1.070 & 6 & Moderate \\
\hline 4 & Modern technologies promote a culture of patience among students & 3.28 & 1.029 & 7 & Moderate \\
\hline & Total & 3.50 & .636 & & Moderate \\
\hline
\end{tabular}

*The means are listed based on the descending order

Based on table (5), the means are within the range of 3.28-3.68. Statement (6) shows a mean of 3.68 which is high and ranked first. It states the following: (Modern technologies facilitate the way students communicate with each other). The standard deviation of the latter statement is 1.119. Statement (4) shows a mean of 3.28 which is moderate \& ranked last. It states the following: (Modern technologies promote a culture of patience among students). The standard deviation of the latter statement is 1.029.It was found that modern technologies play a moderate role in promoting social values among the students enrolled at the faculty of educational sciences at the University of Jordan. That's because the overall mean is 3.50. The total standard deviation is 0.636 
Table (6): Means, and standard deviations, levels and ranks of the role of modern technologies in promoting humanitarian values

\begin{tabular}{|c|l|c|c|c|c|}
\hline No. & Statement & Mean & Std. & Rank & Level \\
\hline 12 & $\begin{array}{l}\text { Modern technologies promote awareness among students about } \\
\text { the significance of personal freedom }\end{array}$ & 3.52 & .966 & 1 & Moderate \\
\hline 14 & $\begin{array}{l}\text { Modern technologies encourage students to collaborate with each } \\
\text { other }\end{array}$ & 3.49 & 1.035 & 2 & Moderate \\
\hline 11 & $\begin{array}{l}\text { Modern technologies promote awareness among students about } \\
\text { the significance of community service }\end{array}$ & 3.47 & 1.053 & 3 & Moderate \\
\hline 8 & Modern technologies promote integrity among students & 3.43 & 1.083 & 4 & Moderate \\
\hline 10 & $\begin{array}{l}\text { Modern technologies encourage students to accept the ones who } \\
\text { are different from them }\end{array}$ & 3.43 & 1.060 & 5 & Moderate \\
\hline 13 & $\begin{array}{l}\text { Modern technologies provide students with opportunities for } \\
\text { engaging in religious dialogue }\end{array}$ & 3.27 & 1.087 & 6 & Moderate \\
\hline 9 & Modern technologies promote tolerance among students & 3.25 & 1.004 & 7 & Moderate \\
\hline & Total & 3.41 & .645 & & Moderate \\
\hline
\end{tabular}

*The means are listed based on the descending order

Based on table (6), the means are within the range of 3.25-3.52. Statement (12) shows a mean of 3.52 which is moderate and ranked first. It states the following: (Modern technologies promote awareness among students about the significance of personal freedom). The standard deviation of the latter statement is .966. Statement (9) shows a mean of 3.25 which is moderate and ranked last.. It states the following: (Modern technologies promote tolerance among students). The standard deviation of the latter statement is 1.004.It was found that modern technologies play a moderate role in promoting humanitarian values among the students enrolled at the faculty of educational sciences at the University of Jordan. That's because the overall mean is 3.41 . The overall standard deviation is 1.0004

Table (7): Means, and standard deviations, levels and ranks of the role of modern technologies in promoting national values

\begin{tabular}{|c|l|c|c|c|c|}
\hline No. & Statement & Mean & Std. & Rank & Level \\
\hline 19 & $\begin{array}{l}\text { Modern technologies enable students to participate in national } \\
\text { events }\end{array}$ & 3.82 & .930 & 1 & Moderate \\
\hline 20 & $\begin{array}{l}\text { Modern technologies promote awareness among students about } \\
\text { the significance of fighting against corruption }\end{array}$ & 3.45 & 1.058 & 2 & Moderate \\
\hline 21 & $\begin{array}{l}\text { Modern technologies encourage students to comply with the } \\
\text { university regulations }\end{array}$ & 3.44 & 1.075 & 3 & Moderate \\
\hline 15 & $\begin{array}{l}\text { Modern technologies participate in fostering national identity } \\
\text { among students }\end{array}$ & 3.32 & 1.127 & 4 & Moderate \\
\hline 18 & $\begin{array}{l}\text { Modern technologies participate in promoting knowledge about } \\
\text { national values }\end{array}$ & 3.13 & 1.099 & 5 & Moderate \\
\hline 16 & Modern technologies participate in fighting against fanaticism & 2.99 & 1.106 & 6 & Moderate \\
\hline 17 & $\begin{array}{l}\text { Modern technologies encourage students to give priority to the } \\
\text { public interest over the personal interest }\end{array}$ & 2.99 & 1.125 & 7 & Moderate \\
\hline & Total & 3.31 & .666 & & Moderate \\
\hline
\end{tabular}

*The means are listed based on the descending order Based on table (7), the means are within the range of3.31-3.82. Statement (19) shows a mean of 3.82which is moderate and ranked first. It states the following: (Modern technologies enable students to participate in national events). The standard deviation of the latter statement is 0.930 . Statement (17) shows a mean of 2.99 which is moderate and ranked last. It states the following: (Modern technologies encourage students to give priority to the public interest over the personal interest). The standard deviation of the latter statement is 1.125 . It was found that modern technologies play a moderate role in promoting national values among the students enrolled at the faculty of educational sciences at the University of Jordan. That's because the overall mean is 3.31 which is moderate. The overall standard deviation is 0.666.

\section{Results and discussion related to the second question:}

Q.2 Is there any statistically significant difference -at the statistical significance level of $(a=0.05)$ - between the respondents' attitudes which can be attributed to gender and academic year?

To answer this question, means, and standard deviations were calculated. That was done to identify the respondents 'attitudes in accordance with the gender and academic year 
Table (8): The attitudes of respondents towards the role of modern technologies in promoting values in accordance with gender

\begin{tabular}{|c|c|c|c|c|c|c|c|}
\hline Area & Gender & Frequency & Mean & Std. & T value & Degree of freedom & Sig. \\
\hline \multirow{2}{*}{ Social values } & Female & 244 & 3.52 & 0.638 & \multirow[t]{2}{*}{1.256} & \multirow[t]{2}{*}{318} & \multirow[t]{2}{*}{.210} \\
\hline & Male & 76 & 3.42 & 0.629 & & & \\
\hline \multirow{2}{*}{ humanitarian National } & Female & 244 & 3.41 & 0.630 & \multirow[t]{2}{*}{.366} & \multirow[t]{2}{*}{318} & \multirow[t]{2}{*}{.714} \\
\hline & Male & 76 & 3.38 & 0.694 & & & \\
\hline \multirow{2}{*}{ National values } & Female & 244 & 3.31 & 0.691 & \multirow[t]{2}{*}{.041} & \multirow[t]{2}{*}{318} & \multirow[t]{2}{*}{.968} \\
\hline & Male & 76 & 3.30 & 0.584 & & & \\
\hline \multirow{2}{*}{ Aesthetic values } & Female & 244 & 3.52 & 0.638 & \multirow[t]{2}{*}{1.217} & \multirow[t]{2}{*}{318} & \multirow[t]{2}{*}{.225} \\
\hline & Male & 76 & 3.44 & 0.524 & & & \\
\hline \multirow{2}{*}{ Total } & Female & 244 & 3.44 & 0.512 & \multirow[t]{2}{*}{.856} & \multirow[t]{2}{*}{318} & \multirow[t]{2}{*}{.393} \\
\hline & Male & 76 & 3.38 & 0.492 & & & \\
\hline
\end{tabular}

Based on table (8),it was found that there isn't any statistically significant difference -at the statistical significance level of $(a=0.05)$ - between the respondents' attitudes which can be attributed to gender. That applies to all the areas jointly and separately.

The latter result is attributed to the fact that Jordanian female and male students have adequate cultural and intellectual awareness, especially about the use of modern technologies. In addition, the use of modern technologies isn't restricted to a specific gender. In fact, modern technologies can be accessed by all people.

The latter result is inconsistent with the result concluded by: Al-Shamas (2005). The latter researcher found that there are statistically significant differences between the respondents' attitudes which can be attributed to gender, for the favor of males. The latter result is inconsistent with the result concluded by Al-Mbaydeen (2009). The latter researcher found that there are statistically significant differences between the respondents' attitudes which can be attributed to gender for the favor of females. The latter result is inconsistent with the result concluded by Kara \& Tekin (2017). The latter researchers found that there are statistically significant differences between the extent of complying with humanitarian values which can be attributed to gender for the favor of males.

\section{Second: Academic year:}

Means, and standard deviations were calculated. That was done to identify the respondents' attitudes in accordance with the academic year

Table (9): Means, and standard deviations of the respondents' attitudes in accordance with the academic year

\begin{tabular}{|c|c|c|c|c|}
\hline Variable & Academic year & Frequency & Mean & Std. \\
\hline \multirow{2}{*}{$\begin{array}{c}\text { The role of modern } \\
\text { technologies in } \\
\text { promoting values }\end{array}$} & $1^{\text {st }}$ year & 93 & 3.49 & 0.656 \\
\cline { 2 - 5 } & $2^{\text {nd }}$ year & 114 & 3.39 & 0.630 \\
\cline { 2 - 5 } & $3^{\text {rd }}$ year & 84 & 3.37 & 0.623 \\
\hline
\end{tabular}

Based on table (9), it appears that there are differences between the respondents' attitudes which can be attributed to academic year. In order to identify the statistical significance of these differences, one-way analysis of variance (ANOVA) was conducted. The results of the latter analysis are presented in table (10) below Table (10): The results of the one-way analysis of variance (ANOVA) for identifying the statistical significance of the differences attributed to the academic year

\begin{tabular}{|c|c|c|c|c|c|}
\hline Source of variance & Sum of squares & Degree of freedom & Mean square & F value & Sig. \\
\hline Between groups & 1.206 & 3 & .402 & 1.572 & .196 \\
\hline Within groups & 80.794 & 316 & .256 & & \\
\hline Total & 82.000 & 319 & & & \\
\hline
\end{tabular}

Based on table (5), it was found that there isn't any statistically significant difference -at the statistical significance level of $(\mathrm{a}=0.05)$ - between the respondents' attitudes which can be attributed to the academic year. The latter result is attributed to the fact that the use of modern technologies (e.g. computers and smart devices) is not restricted to a specific category. In fact, modern technologies are used by all students of all academic years. It should be noted that modern technologies play a significant role in promoting values among young people. That applies whether young people are enrolled in a university or not.

\section{Conclusion}

The researchers found that modern technologies play a moderate role in promoting values among the students enrolled at the faculty of educational sciences at the University of Jordan. That is concluded from the perspective of the students themselves. That applies to aesthetic, social, humanitarian and national values jointly and separately. The latter result may be attributed to the fact that there isn't any control enforced over the content posted on the web pages, including social media pages. Thus, anyone can use the web pages to promote negative 
values. For instance, terrorists can use the web to promote terrorist ideas.

\section{Recommendations}

In the light of the study's results, the researchers recommend the following:

1- Using social media by Jordanian universities in order to promote positive values among students

2- Engaging students more in the process of creating social media content that aims at promoting values among students. That should be done whether the content is posted on pages for the university or student assemblies, such as: the student council.

3- Conducting further studies about the promotion of values among university students. The researchers also recommend conducting students that aim at examining the role of each social media platform in promoting values among the students

\section{References}

Abdullah, Mohammad (2014). Adolescence and the way of dealing with adolescents. Amman. Jordan. $1^{\text {st }}$ edition. Dejlah publishing and distribution house

Abed Al-Qader, Mohammad (2011). Ethical issues in the light of the Islamic ideology. Alexandria. Egypt. AlMa'refah Al-Jamey'ya publishing and distribution house

Abeed, Ibrahim (2006). Educational means and technology. Amman. Al-Maseera publishing and distribution house

Abu Al-Naser, Medhat (2008). Values and ethics that govern work and administration. $1^{\text {st }}$ edition. Al-Alameye publishing and distribution house. Al-Jeeze. Egypt.

Aggarwal, A. (2001), Web-Based Education (WEB) and Diffusion, proceedings of the 9th European conference of Information Systems" Global co- Operation in the New Millennium “ Bled, Solvenia,pp1121- 1122.

Al-Abideen, Fatmeh (2014). The impact of social media on social values among the students enrolled at Jordanian universities: A social study. Unpublished PhD dissertation. The University of Jordan. Amman. Jordan

Al-Agha, Mira Bassam, and Esleem, Nour Yahya (2018). The role of social media in promoting social values among the students enrolled at Palestinian universities and methods for activating this role. A research published on the following link: https://core.ac.uk/download/pdf/130674106.pdf Retrieved on: 1-11-2019

Al-Aqil, Ismat and Al-Hyari, Hasan (2014). The role of Jordanian universities in promoting citizenship values. The Jordanian Journal of Educational Sciences. Amman. Jordan 10(4). 517-529

Al-Ash'ab, Nawal (2015). E-learning: Modern trends in the educational system. Amman. Jordan. Amjad publishing and distribution house.

Al-Dali, Shaima' and Al-Laithi, Huda (2016). The Effect of using Social Networking Site on Rural College Students Values. The Journal of the Humanitarian Studies Faculty. Issue of December

Al-Fayrooz, Abadi Mohammad (1994). Al-Muhit Dictionary. Beirut. Al-Resaleh Institution. $4^{\text {th }}$ edition.

Al-Helalat, Haya (2016). The role of technology in initiating a value-based conflict among young people in the Jordanian family: (Phone mobiles and Facebook as models). Unpublished $\mathrm{PhD}$ dissertation. Mu'tah University. Karak. Jordan

AljaadNawal(2016). The role of social communication Tools in Education from the Saudi Female Student's Perceptions. International Education Studies, vol. 9, No. 8 published by Canadian center of science \&Education (194-202)

Al-Jamal, Rabab (2013). The impact of using social media on the ethical and value systems of young Saudi individuals at the journalism department. Unpublished MA thesis. Faculty of communication. King Abed AlAziz University. Jeddah.

Al-Kreety, Reyad and Manhi, Murtada (2014). The reality of using educational technologies in the special education classroom in Babel. The Journal of the primary education college for Human and Educational Sciences. Babel University. Issue 18. 482-498

Al-Madani, Osama (2015). The role of social media in forming public opinion among Saudi university students (Umm Al Qura University as a model). The social sciences and art journal. Sultan Qaboos University (395425).

Al-Omari, Asma' (2015). The extent of complying with values among the students enrolled at Jordanian universities from the students' perspective. Vol 42. Issue. 3

Al-Qaba', Mandal (2012). Aesthetic values and their impact on behavior. Al-Jazeera Newspaper. Saudi Arabia. 9/1/2012. Issue 14347.

Al-Qasas, Mahdi (2010). E-learning: Critical analysis. The E-learning Journal. Al-Mansoura University. Egypt. Issue No. 5

Al-Sayed, Ibrahim (2005). The value system and its relationship with socialization and motivation to achieve: A field study targeting a sample of Indonesian, and Malaysian students who are enrolled at Egyptian 
universities. Unpublished PhD dissertation. Zagazig University. Zagazig. Egypt

Al-Shahin, Ghanem Abdullah (2010). The impact of social, religious, and economic values on the attitudes of the teachers who are still students at the teacher development institutions towards the teaching profession. The educational sciences journal. 11(2). 154-178 .Bahrain.

Alshraah, M. (2017). The Effect of using Social Networking Sites on the Moral and Religious Value System among Hashemite University Students in Jordan. Dirasat Journal. 44(4)

Al-Shamas; Issa (2005). The impact of foreign TV channels on young individuals: A field study targeting the students enrolled at the faculty of education in Damascus University. The Journal of Damascus University. 21(2). 11-44.

Al-Sharqawi, Mousa (2005). The awareness of university student about citizenship values: A field study. The Journal of Studies in University Education. 9. 112-129

Al-Sharqi, L.; Hashim, K.; and Kutbi, I. (2015). Perceptions of Social Media Impact on Students' Social Behavior: A Comparison between Arts and Science Students. International Journal of Education and Social Science. 2(4).

Al-Shboul, Mohanad; and Alyan, Rebhi (2014). E-learning. Amman. Jordan. Safa' publishing and distribution house.

Al-Tayar, Maha (2014). Social media and its impact on values among university students (Twitter as a model). The Arab Journal for Security Studies and Training. Reyad. Saudi Arabia. 31(61). 193-226

Al-Yousif, Shua'a (2012). Modern technologies: Advantages and disadvantages. A study for the negative impacts Kotob Al-Umeh publishing and distribution house. A research published on the following link: Islamweb.net/new library/display-umma.phd?lang=\&BabId=1\&chapterId

Al-Zboun, Mohammad and Ateyeh, Nariman (2018). The negative impacts of modern communication technologies on raising up adolescents from the perspective of the teachers working at the schools affiliated with the Ministry of Education in Jordan. The Educational Sciences Journal. The University of Jordan. 46(2). Appendix 1(197-2010).

Al-Zboun, A.; Abu Melhem, M,; and Al-Awamleh, A. (2017).The Impact of Digital Social Media on Shaping the Value System for Ajloun University College Students. The Jordanian Journal of Social Sciences. 10(3).

Al-Zyood, Majid (2006). Young individuals and values in a changing world. Al-Shorouq publishing and distribution house. Ramallah.

Ata, Ameera (2010). YouTube. The Journal of E-learning. Al-Mansoura University. Egypt. Issue 5. Page 13

Athamneh, Naziha (2017). The impact of social media on the social values of university students: A field study targeting a sample of students enrolled at Masila University. Unpublished MA thesis.

Hasan, Isamail (2010). Blended learning. The E-learning Journal. Al-Mansoura University. Egypt. Issue No. 5

Kim, Hae-Young (2015). Statistical notes for clinical researchers: post-hoc multiple comparisons. Restorative dentistry and endodontics (RDE) journal. 40(2)

Lawless H.T., and Heymann H. (1999) Descriptive Analysis. In: Sensory Evaluation of Food. Food science text series. Springer, Boston, MA

Mahdi, Kathem (2002). Psychological values and the top five personality traits. Al-Yarmouk Research Journal: Social and Human Sciences Series. 3(2). 12

Mahmoud, Yousif (2009). Sociology and technology. $3^{\text {rd }}$ edition. Amman. Jordan. Wa'el publishing and distribution house.

Marian, T and Dumitrina, B(2003), coned project: Aweb Based Virtual University ,Department of computer science, Technical University of Cluj-Napoco publications, Romania

Mathur, S. and Corley, K (2014), Bringing Ethics into the Classroom: Makinga Case for Frameworks, Multiple Perspectives and Narrative Sharing. International Education Studies, 7 (9): 136-147h published by Canadian center of Science and Education.

Mattar, Ameera (2006). Values, and mind in the light of philosophy and civilizations. Egypt. Ayn Journal for Social and Human Studies and Research

Michale, V, (2010). Facebook and the invasion of technological communities, New YORK University, NewYork,USA.

Naser, Ibrahim (2016). Ethical education. $2^{\text {nd }}$ edition. Amman. Jordan. Wa'el publishing and distribution house.

Patrick, E.(2001).Personal Value Systems and Decision-Making Styles Of Public Managers, Public Personnel Management.

Rafter, J.; Abell, M.; and Braselton, J. (2002). Multiple Comparison Methods for Means. Society for Industrial and Applied Mathematics. 44(2).259-278

Ross,H \& Banow, R \& Yu , S(2015). The use of twitter in large lecture courses: do the students see a benefit? Contemporary Educational Technology,6(2), 126-139

Salem, Mohammad Nazmi (1984). Aesthetic values. Al-Ma'aref publishing and distribution house. Alexandria.

Satel, Salwa (2018). The extent of using modern technologies and its impact on the creativity of the students 
enrolled at the public secondary schools in Palestine from the teachers' perspective. Al-Najah University. Unpublished MA thesis. Nables. Palestine

Shbeeta, Maha (2014). The impact of using social media website and personal websites on family dialogue from the perspective of parents. Unpublished MA thesis. Al-Najah University.

Acknowledgment

The researchers would like to thank their families for providing them with much support. They would like to thank the management of the University of Jordan for providing them with support 